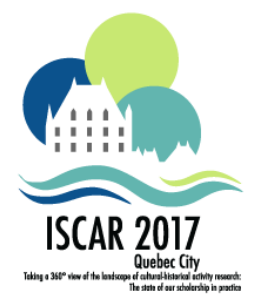

\title{
Cultural-Historical Scientific School: The Issues That L. S. Vygotsky Brought Up*
}

Vitaly V. Rubtsov

RECTORAT@LIST.RU

Moscow State University of Psychology and Education

Moscow, Russia

\begin{abstract}
The report highlights the fundamentals of L.S. Vygotsky's cultural-historical theory and discusses the system of concepts of this scientific school. The report analyses L.S. Vygotsky's approach, according to which the basis for the development of human psyche is created by a qualitative change of the social situation or, in A.N. Leont'ev's terms, by a change of human activity. The importance of intelligence and emotions, which are internally connected, is demonstrated in relation to the change of human activity. The role of social interactions in learning and development of children is discussed referring to the challenges of the "new school".
\end{abstract}

Keywords: Cultural-historical scientific school; The change of social situation; The change of human activity; The zone of proximal development; Social interactions and learning; Collective activity.

*. Rubtsov, V. V. Report on the International Symposium devoted to L. S. Vygotsky's 120th anniversary "Scientific School of L. S. Vygotsky: Traditions and Innovations" Materials of the international symposium (July 27-28 2016) - M., "Bukivedi", 2016. P. 18-24. 


\section{The Fundamentals of the Cultural-Historical Theory}

I will discuss these fundamentals referring to a large extent to the point of view of my teacher, Davydov (1995). In his opinion, the foundations of the cultural-historical concept were laid down by L. S. Vygotsky himself around 1927-28. Later he contributed largely to the development of these fundamentals. But both during Vygotsky's life and after his demise, a significant part in disclosing the very essence of this concept, its elaboration and specification played his direct students, and later - his followers. To Vygotsky's direct students belong preeminently A. N. Leontiev, A. R. Luriya, L. I. Bozhovich, A. V. Zaporozhets, D. B. Elkonin, P. Ya. Galperin. According to V. V. Davydov, it is impossible to grasp the essence of the cultural-historical concept without taking into account that it was to a large extent elaborated, clarified, extended, modified and refined by Vygotsky's students and followers - that is, by his scientific school. Interestingly enough, already in the 1930-s during Vygotsky's lifetime quite an original theory for that time emerged - the general psychological activity theory, created preeminently by the efforts of $\mathrm{A}$. N. Leontiev and his followers. In the opinion of V. V. Davydov, activity theory represents the direct successor to those principal ideas, which were put as a basis of the cultural-historical concept by Vygotsky himself.

In this regard, Davydov criticizes those psychologists who argue that Vygotsky did not apply the notion of activity. In Davydov's judgment, Vygotsky, being a connoisseur of German Classical Philosophy and a true Marxist, could not pass by Marx's distinguished works dedicated to the problems of activity. Already from the beginning of 1925, Vygotsky began to thoroughly examine the social-historical notion of activity and its application in psychology. Therefore, we should believe Leontiev when he claims that in 1925, Vygotsky began to elaborate the social-historical notion of activity in the context of psychology, and he made a few steps in that direction. The fact that Vygotsky had a truly substantial socialhistorical and partly psychological concept of activity is evidenced by several remarkable pages in one of his articles (which unfortunately had not been published until 1984), where he openly and directly used the term "activity" as a concept and demonstrated that human life, in comparison to the one of animals, is aimed at the future and becomes free by virtue of tools and words. Some of Vygotsky's ideas, particularly those referring to the social conditions of human development, were deepened by A. N. Leontiev already on the basis of his quite elaborated psychological understanding of activity. Without distorting anything in the essence of Vygotsky's approach to conditions of human development, Leontiev replaced the term "social situation" with the notion of "development of activity".

The fundamentals of the cultural-historical theory of Vygotsky, Leontiev and the whole Vygotskian scientific school were consistently articulated by V. V. Davydov. In his interpretation, they are presented in the following way:

First: the basis for the development of a human being is represented by a qualitative change in social situation, or, in terms of Leontiev, a change in person's activity. 
Second: universal points of human's mental development are represented by learning and upbringing.

Third: the initial form of activity is its full-form execution by the person on the outer social or collective - plane.

Fourth: psychological neoformations, which emerge in a human being, are derivative from the interiorization of the initial form of human activity.

Fifth: significant role in the process of interiorization belongs to different sign and symbol systems.

And finally, sixth: an important part in the activity of human consciousness belongs to the internal unity of intelligence and emotions. Without going into detail on these principles of cultural-historical psychology, V. V. Davydov still remarks that the issue of unity of intelligence and emotions had not been elaborated enough. And this is an important challenge in the organization and analysis of the research results by contemporary researchers. The point is, that on the one hand L. S. Vygotsky considers meaning as a unit of the development of the psyche. As we know, according to Vygotsky, giving meaning to a meaningless word represents the main way of the formation of scientific concepts (in contrast with spontaneous concepts). On the other hand, Vygotsky considers pereghivanie as a unit of the development of the psyche, the nature of which is connected with commonality, communication and certainly with the emerging emotion. What is the relationship between "meaning" and "pereghivanie"? This question is directly connected with the issue of the connection between intelligence and emotions.

V. V. Davydov also argues, that till now the notion of collective activity (brought into psychological science by Vygotsky himself) has still not been elaborated. Moreover, since collective activity exists, then consequently its bearer is a collective entity, a collective subject. The concept of collective activity and collective subject is also a new problem (though it has been raised long ago), which needs to be explored and elaborated on the contemporary level. However, if we are not able to say anything plainly about collective and social forms of human activity, then what can we say about the so-called interiorization, which Vygotsky and his followers perceive as a process of transformation of collective activity into individual activity, and of collective subject into individual subject?

V. V. Davydov also clarifies some aspects of Vygotsky's approach to human development. For instance, Vygotsky's ideas had been evolving from his first publication in 1915 to the end of his life. He had never had clear and definite terminology, because the theory that he was working on could not be elaborated as fast as he aspired. At the same time, considering his general point of view, a child is born into a social situation, into a communal situation as a human being with all the inherent potential, and develops further as a social and communal being. This also provides much food for thought.

Surely those six principles of the cultural-historical concept formulated by Vygotsky require serious and detailed experimental and theoretical working-through. However, I 
would like to point out again that according to Vygotsky the beginning of human development is a collective (communal, joint) or social activity carried out by or with the assistance of a collective subject in a cultural environment. The mediums of the culture are signs and symbols. It is thanks to signs and symbols that in the process of learning and upbringing the individual activity of a person becomes important, and the individual subject becomes clear, and then said subject gains individual consciousness. So, in the very general outline, the pattern of origin of the individual consciousness is this: collective-social activity, culture, signs and symbols, individual activity, individual consciousness.

While attempting to highlight the singularity of the cultural-historical theory, it is crucial to keep the original point of view of L. S. Vygotsky himself - to distinguish between the theory and its interpretation in the framework of the activity approach, elaborated by A. $\mathrm{N}$. Leont'ev. It is crucial to avoid reducing cultural-historical theory to cultural-historical activity theory. Doing so, means not taking into account L. S. Vygotsky's idea that the notion "change of social situation" corresponds to the notion "development of activity" in the framework of the activity approach. These notions correlate. However, they are defined in different systems of coordinates - in the framework of the cultural-historical theory on the one hand and in the framework of the activity approach on the other hand.

As I have already mentioned this highlights the singularity of each of the theories and illustrates the history of the development of L. S. Vygotsky's scientific school, below I will briefly discuss the meaning of the main concepts of the cultural-historical theory and those issues that are challenging for contemporary research, conducted in the framework of L. S. Vygotsky's scientific school.

\section{Social Situation of Development. "Zone of Proximal Development"}

As I have already mentioned, in L. S. Vygotsky's cultural-historical theory the social situation is perceived as the source of development (Leontiev, 1981; Luria, 1932; Pyzirei, 1986; Wertsch, 1985). According to Vygotsky, "any function in the cultural development of a child appears twice, in two aspects, first in a social plane and then in a psychological plane, first between two people as an inter-psychic category, and then inside of a child as an intra-psychic category" (Vygotsky, 1978, p. 145). Social interactions appear to be genetically social, moreover in its primary form any function is shared among the participants of interaction. "All superior psychic functions and their inter-relations have at their back those genetically social relations, real relationships, homo duplex (the man doubled, lat.). Hence the principal and the method of personification in cultural development research, i.e. dividing functions between people, personification of functions. Take voluntary attention, for instance: one acquires, the other masters. It's separating again of that which has been merged into one (compare to modern labor)" (Pyzirei, 1986, p. 54).

Social interactions define the mechanism of distribution of functions on the one hand and the means or method of mastering those functions on the other hand. Thus, for example, guided social interactions, which initially serve as instruments for social realization 
of the processes of cognition and communication later begin to play the role of the cognitive function of self-regulation and mental representation of various kinds of information. These social interactions activate the not yet developed cognitive functions, which allows the student to act on a higher cognitive level. The gap between that which a learner is able to do on his /her own (the actual level of development) and that which he/she is capable of with proper guidance is called "zone of proximal development". Therewith, according to Vygotsky, learning is successful only when it goes ahead of development, when it awakens and brings to life those functions, which are yet in the process of maturing or are in the zone of proximal development. This, in his view, is the way how education plays a crucial role in development (Griffin \& Cole, 1988; Vygotsky, 1978).

\section{Social Interactions and Education}

We can say that two ideas, formulated by Vygotsky, became cornerstones of the new approach to the issue of learning activity. First is that scientific community clearly realized that social interactions and cognitive development are neither mixed nor independent processes, they are also not reversible (in the sense of "isomorphic") processes, they are not even equivalent processes. They rather are interdependent processes, since generation and development of the one internally depends on development of the other. Deriving benefit and getting effect from specific social interactions, which means really finding oneself in the space of development and making a step up in one's own achievement, is possible for a child, when there is a certain correspondence to the actual developmental level. But this actual level itself is also the result of previous and future social interactions.

Another important issue is that content of the notion "zone of proximal development" suggests a new paradigm of development, and accordingly a new approach to teachinglearning psychology. The notion of learning as a natural and individual process, dividing participants of the educational situation into teachers and learners, is being replaced by the view of learning as a process of co-action, co-operation and joint activity (Davydov, 2000). Notably, the key mechanism of this process, which makes it culturally and socially determined, is the mediation of cognitive acts by means of interaction between the participants of activity. In this case a new problem comes to the fore: not only what to teach, but also how to teach, i.e. a problem of organizing effective joint forms of learning activity (Rubtsov, Martin, \& Hall, 1991).

\section{Organizing Joint Learning Activity}

The search for effective forms of co-simultaneity (co-operation as a form of interaction) in Vygotsky's scientific school is related to many researchers' works on the concept of "organization of joint activity" which is characterized by: 
- distribution and exchange of actions;

- mutual understanding;

- communication;

- reflection as a special kind of operation with modes of cooperative work.

The concept of joint-distributed action (co-action) is a way to refine Vygotsky's idea of distribution of a psychological function as a condition of mastering it in a social situation. Method of research on properties of organization of joint activity in relation to the genesis of cognitive actions in a child has a paramount importance in this regard. Distinctiveness of this method is due to modeling of interaction situations with the help of sign meansschemes and activity models. And its prototype is represented by the method of double stimulation of L. S. Vygotsky - L. S. Sacharov (Vygotsky \& Sacharov, 1998). In such models, researchers generally record structure of individual actions, manner of their distribution between participants and sequence of their implementation. Working with such scheme gives a group of children a possibility to organize their communication and cooperation by recording in it the changes of the interaction modes, which correspond to different strategies of problem solving. This method of researching interactions in relation to genesis of learning-cognitive actions, which is based on the application of numerous sign schemes and models of activity, is in part an important result of social-genetic psychology of learning activity, which we have developed (Rubtsov, 2008).

\section{On the Issue of Training Researchers of Social Practice in the Framework of the Scientific School of L. S. Vygotsky, A. N. Leont'ev, A. R. Luriya ${ }^{1}$}

Today, the ideas of the cultural-historical theory and activity approach are perceived as fundamental methodological principles, which allow to study the issues of social practice. Therefore, an important question is: what does it mean to study various kinds of social practice (e.g. educational practice) through the prism of the system of concepts of the cultural-historical theory and activity approach? The answer to this question is connected with the elaboration and organization of the Master's program "Cultural-historical psychology and activity approach in education". This program was elaborated and is run in Moscow State University of Psychology and Education and is aimed at training of specialists, capable of studying peculiarities and challenges of child development in education (Rubtsov \& Guruzhapov, 2016).

In the framework of the first basic module "Methodology of psycho-pedagogical research: activity approach" of the Master's program, the students get acquainted with the theoretical challenges of the cultural-historical theory and activity approach. In the framework of this module, they are also introduced into the system of concepts of the

1. The experience of running a Master's program: «Cultural-Historical Theory and Activity Approach in Education». 
cultural-historical school and get acquainted with the research conducted by Vygotsky's direct disciples and followers.

An important part of training is connected with studying methods of research and their application in the analysis of the challenges of social practice. Thus, the program's second module which is called "Methods of psycho-pedagogical research" is aimed at training the capacity of applying the methods of cultural-historical psychology and activity approach in analyzing challenges of the educational activity and various issues connected with its organization (interaction of participants, distribution of actions, roles, positions, processes of communication and reflection).

In this module, special emphasis is placed on the students' practical application of the method of double stimulation of Vygotsky-Sacharov. The content of this method often becomes the issue for serious discussions. I would like to note, that Vygotsky regarded acquisition of meaning in a meaningless word as the main way of child's development. Thus, it is impossible to grasp the specifics of the developmental act without understanding Vygotsky's idea on how meaning emerges in a child, how in the interaction between the child and adult a directed emotion emerges and finally how the child himself gains the meaning that originally the adult possesses.

In the framework of the third module: "Theoretical and experimental challenges in research on education and development" each student can choose one of the following fields of specialization: preschool education, primary education, secondary education and inclusive education. Education and development of children in each of these fields are connected with specific methods, however the fundamentals of the cultural-historical tradition and activity approach underlie all of them. The program presupposes that in the process of specialization the students will not only get acquainted with new approaches, but on the basis of the general methodology they will be also able to address a wide spectrum of research activities, aimed at resolving practical tasks of contemporary education. As a matter of fact, the courses of this module allow the students to acquire practical skills of working with children on various stages of their development and study the challenges of education in the system of concepts of the cultural-historical psychology and activity approach.

It is important to highlight the competences that the students need to succeed in our program. They include:

- capacity to plan and model new forms of joint leaning activity, corresponding with the zone of proximal development and the age of the students;

- capacity to conduct targeted psycho-pedagogical research on the specifics of the organization of the learning activity and to define new requirements to the organization of joint learning activity;

- capacity to fulfill new forms of organizing learning activity in teamwork (crossdisciplinary cooperation); 
- capacity to assess the students' educational results, which are determined by the structure and general patterns of the organization of learning activity, as well as by age and individual differences;

- capacity to reflect on one's own professional achievements, perform professional development on the basis of the conducted psycho-pedagogical research.

Acquisition of certain research competences allows to speak of special professional actions, performing of which corresponds with the system of concepts of the culturalhistorical theory and which are necessary for studying concrete challenges in organizing learning activity. In the most general way, this system is characterizing by something that we call "the general means of researching learning activity". Together with acquiring professional competences in the field of scientific and research activity, the formation of this means may be considered as the principal result of the Master's program "Culturalhistorical psychology and activity approach in education".

Let me also speak of the system of special actions that are characteristic of this type of research in learning activity. It includes:

- spotting a fragment of the learning activity and a typical problem (challenge) of its organization and development;

- fixating and representing of the fragment of the learning activity in special signsymbolic schemes and models with the aim of its transformation and analysis "as it is";

- modeling means and ways of organizing learning activity with the aim of creating new forms of joint work and spotting the "step of development" in the learning activity that marks the transition to a new, more efficient form;

- grounding the means and ways of changing the learning activity and defining the stages of constructing its new form;

- defining the roles and possible positions of the participants, who develop the learning activity in teamwork;

- control and assessment of the students' educational results, achieved in the process of development of the learning activity;

- assessment of the development of one's own professional achievements in the situation of professional communication, discussion and presentation of the research results in professional community.

One of the ways of assessing the development of professional actions in the framework of the master's program is represented by project-research tasks. These tasks are performed by the students at the very beginning and at the end of each module. At the same time, 
it is necessary to note that assessment of the development of the professional action is a complex one. It is based on the opinion of the student's research supervisor, specialists of the educational institution where the student is conducting research and sometimes parents of the children. The representatives of the professional community necessarily take part in assessing the students' achievements. The very process of conducting research also necessarily becomes the issue of discussion by the professional community. The assessment is also based on the results of the students' participation in various forms of scientific interactions (seminars, conferences, discussions) and on the results of the students' personal scientific activity (publications in scientific journals, reports, papers and presentations). The latter testifies of the students' personal achievements and is a part of the individual portfolio.

Thus, what factors contribute to the program's efficiency?

First, the disciplines of each module are aimed at the formation of the students' theoretical and methodological knowledge, necessary for conducting psycho-pedagogical research. They are based on the fundamentals of the cultural-historical psychology and activity approach.

Second, the formation of research competences in students is based on their profound practical work, which is possible due to an elaborated network of educational institutions that provide possibilities for traineeship and practical acquisition of efficient patterns of learning activity (kindergartens, schools, gymnasiums, centers of psycho-pedagogical support etc). Practical work in the institutions offering the best patterns of social practice is the key condition of training future specialists.

Third, the educational process of the master's program contributes to the development of the students' professional community and their inclusion into a vast system of professional communication, which is a necessary condition for the development of professional reflection.

Our experience testifies that specialists trained in the framework of this program are able to perform practice-oriented psycho-pedagogical research, study the challenges and specifics of the learning activity, model new ways of organizing learning activity of adult and children, which contribute to the development of children in the educational process. There is a strong demand for such specialists in various kinds of educational institutions, where development of the educational environment is one of the priorities of professional work. The program's graduates are able to study and solve the problems of developing educational environment on the basis of the ideas and concepts of the cultural-historical psychology.

Cultural-historical theory, especially its interpretation in the framework of the activity approach, is a grand contribution to modern science. At the same time, as V. V. Davydov noted: "Vygotsky's cultural-historical concept even in its interpretation in the framework of the activity approach is still not truly a theory, but rather a hypothesis. But, as you know, true science finds the source of its development in formulating theories and proving 
their legitimacy for different areas of social practice. It is the challenge to young scholars philosophers, logicians, psychologists, educators, culture studies experts - who are able in the nearest future (hard to say how many years from now) to turn this cultural-historical hypothesis into a full-scale truly fundamental modern theory".

\section{References}

Davydov, V. V. (1995). Report on the international conference: "Cultural-historical approach: Development of humanities and education". In Last talks (pp. 30-35). Moscow: Experiment.

Davydov, V. V. (2000). Types of generalization in instruction: Logical and psychological problems in the structuring of school curricula. soviet studies in mathematics education. Moscow: Russian Pedagogical Society.

Griffin, P., \& Cole, M. (1988). A dialogue with future through today's activity cognition and communication. Science, 189-207.

Leontiev, A. N. (1981). The problem of activity in psychology. In J. V. Wertsch (Ed.), The concept of activity in soviet psychology (pp. 140-162). New York: M. E. Sharpe.

Luria, A. R. (1932). The nature of human conflicts. New York: Liveright.

Pyzirei, A. A. (1986). Cultural-historical theory of L. S. Vygotsky and contemporary psychology. Moscow.

Rubtsov, V. V. (2008). Social'no-geneticheskaya psychologiya razvivayushego obrazovaniya: deyatel'nostniy podchod [soci-genetic psychology of developmental education: Activity approach]. Moscow.

Rubtsov, V. V., \& Guruzhapov, V. A. (2016). Designing the master research program taking into account the results of approbation and implementation of the professional standard of the teacher. Psikhologicheskaya nauka i obrazovanie [Psychological Science and Education], 21(2), 12-21. doi: 10.17759/pse.2016210203

Rubtsov, V. V., Martin, L. M., \& Hall, M. J. (1991). Learning in children: Organization and development of cooperative actions. New York: Nova Science Publishers.

Vygotsky, L. S. (1978). Mind in society: The development of higher psychological processes. Cambridge: Harvard University press.

Vygotsky, L. S., \& Sacharov, L. S. (1998). Research on the formation of concepts: Method of double stimulation. Issue III. Subject of cognition. General Psychology.

Wertsch, J. V. E. (1985). Culture, communication and Vygotskian perspectives. Cambridge: Cambridge University press. 